\title{
Challenges of Cambodian Teachers in Contributing to Human and Social Development: Are They Well-Trained?
}

\author{
Chankea Phin
}

\begin{abstract}
Teacher is the nucleus of the whole educational system and is of the significant impact on children's learning. This paper investigates challenges of Cambodian teachers in contributing to their nation's future human and social development. In order to achieve that development, are Cambodian teachers well-trained? To clarify, a questionnaire was distributed to a line of Cambodia's educational staff from local to central. A section of the questionnaire was extracted for this paper. The results revealed that educational development in Cambodia faces severe challenges due to severe shortage of qualified trained teachers. Up to present, some teachers have not experienced in any pedagogical training. Furthermore, despites few officials who are PhD holders, some are primary school graduates or even not finished primary level. Moreover, in-service training has not yet been systematized and has been provided to teachers not regularly. Thus, feasible in-service training programs for Cambodia's teachers appear urgent to be structured for their continuous professional development so as for contributing to human and social development.
\end{abstract}

Index Terms - Cambodia, human and social development, in-service teacher training, quality education, qualified trained teacher.

\section{INTRODUCTION}

For few decades; since the Education For All: EFA goals and the Millennium Development Goals: MDGs were established, remarkable improvement has been gradually succeeded in many countries worldwide, but the goal is not yet achieved due to some hardest challenges remained particularly on the poorest and the most vulnerable [1]. Presently and globally, there are at least 250 million out of 650 million children of primary school-age are failing to learn the basics -those who fail to pursue to grade 4 or do not reach the minimum level of learning, that cannot read or write [2]. The biggest issue is when young people are barely able even to read or write to strive to acquire skills they need to get work in the future. To not only lift economic development and better quality of life, but also to deal with some phenomena such as poverty alleviation, conflict prevention, and environmental protection, education needs to be appropriately improved [3]. It is crucial that education stakeholders are well positioned to make a strong evidence-based case for the central role of teaching and learning, to look at the reforms of curriculum and assessment that needed to enable teachers to fulfill their role in ensuring

Manuscript received July 31, 2013; revised October 1, 2013. This study is financially supported by Honjo International Scholarship Foundation (HISF) http://www.hisf.or.jp/

Chankea Phin is with the Graduate School of Comprehensive Human Sciences, University of Tsukuba, Ibaraki Prefecture, Japan (e-mail: pchankea@human.tsukuba.ac.jp). all children are equipped with proper knowledge and skills in order for becoming a competent teacher in the future, and for contributing to their countries' development or maybe possibly to also the world. Improving the quality of education, needless to say, depends to a wide extent upon the quality of teachers. In other word, quality of education requires quality teachers [4]. Weakness of dealing with the acute shortage of qualified teachers is one among the most serious constraints to achieving the EFA goals and the MDGs. The developments depend on education that has quality teachers as indispensable pillar at its centre. Ensuring quality of all teaching activities and learning environments is a challenge that all countries, regardless of their stage of development, keep focusing.

Like in other countries, Cambodia has put rigorous efforts on effective education reform since the 1980s to restore, reconstruct and develop the country that gets crippled due to the great loss of loads of resources during the civil war in the 1970s. Cambodia shocked the world when the communist Khmer Rouge regime; from 17 April 1975 to 7 January 1979, which exactly lasted three years, eight months, and twenty days, ruled the country under their leader Pol Pot because he assassinated his own Khmer people [5]. Tremendous range of number between one and two million Cambodian were died of starvation, torture or illness; and decimated those who were teachers and other educated Cambodians, when they were suspected of relation with the previous regime [6]. The Ministry of Education, Youth and Sport: MoEYS [7] shows its figure that about 80 per cent of teaching staff disappeared during the turbulent conflict in the 1970s. Cambodian government, in the 1980s, deployed people who survived from the conflict and who were just able to read or write very little to become teacher so as to meet the need of teacher's number to perform at school. Undeniable thing is that, presently, there remains teaching staff that have no pedagogical training experience, particularly teachers who are teaching at the rural areas [8]. Furthermore, vast amount of teachers, who are currently teaching at school and those who are not teaching, hold very low level of academic diploma which are lower secondary education level and primary education level only or even not finished primary school level, although there have been few educational personnel hold $\mathrm{PhD}$ degree [9].

Today, Cambodia is still one of the world's least developed countries. Children, as labor force especially in rural families, have less opportunity to come to school because they have to involve in work to earn money to support their family's daily living. Also, it is because of deficiency of accessible school nearby. Such factors disrupt children's learning opportunity, while more significantly, 
one cannot deny that it is meaningless if children go to school but school faces difficulty in ensuring sufficient number of capable teachers to provide instructions. Competent teachers help thrive schools and contribute to children's learning so they will get confident with their full potential to live a life in the community and to take part in any sector to develop the country in the future. Children must be taught by professional, well-trained, qualified teachers. Thus, teachers must be much more equitably deployed to ensure that children are on quality education. So, every new teacher and teachers who are already in post need to have quality initial and ongoing training. To this mean, unlike published studies of some researchers and reports of some related documents; for example: [10]-[12], that those are investigating teacher education in Cambodia but those are missing the target issue mentioned in this study.

\section{PURPOSE AND OBJECTIVES}

The purpose of this paper is to investigate challenges of Cambodian teachers in contributing to their nation's future human and social development. To this extent, this study started with one hypothesis whether Cambodian teachers are well-trained. More specifically, the following objectives are designed: (1) To seek training topic delivered to Cambodian teachers, (2) To identify place of receiving a training program, (3) To indicate duration of each training program, (4) To know how much allowance that teacher received, (5) To clarify who are supporter for each training program, (6) To obtain respondents' perceptions regarding degree of each training program's usefulness, and (7) To draw respondents' awareness whether or not in-service teacher training program is significant for their professional development.

\section{METHODOLOGY}

The survey instrument was author's self development questionnaire which was designed based on related literature and official documents which were originally written in English, Japanese, and Khmer language. Such this, the author decided to organize it in English, and then translated into Khmer language in order for distributing to respondents. This survey was conducted in August 2012 targeted to a line of educational staff, from local school teachers to central level officials, in Cambodia. 230 copies were distributed and a total of 173 respondents' copies were collected, resulting in a response rate of $75.22 \%$ (See Table I).

TABLE I: NUMBER OF RESPONDENTS BY ENTITY $(N=173)$

\begin{tabular}{lrlr}
\hline \hline \multicolumn{1}{c}{ Respondents by entity } & no & Respondents by entity & no \\
\hline Nursery school teacher & 1 & District education official & 52 \\
Primary school teacher & 48 & $\begin{array}{l}\text { Provincial education } \\
\text { official }\end{array}$ & 20 \\
Lower secondary teacher & 6 & Central official & 11 \\
Upper secondary teacher & 7 & Researcher & 1 \\
University instructor & 6 & Others & 3 \\
Trainers of three various Teacher Training Centers (TTC): & \\
Pre-School TTC in Phnom Penh, Provincial TTC in Svay & 18 \\
Rieng province \& Regional TTC in Prey Veng province & \\
\hline
\end{tabular}

Among these, 9 were distributed to and collected from some educational staff that came from different provinces of Cambodia to stay at teacher's guesthouse in Phnom Penh for a short period for work. All the respondents and responses are kept anonymous and confidential. However, the author notices that the majority of respondents experienced working for any level of school education. In this paper, the author extracts only one section from the whole questionnaire: In-Service Teacher Training Program. This section consists of seven parts that reply to the seven objectives as stated earlier and is the main focus in this paper, but not absolutely because some small related parts of the other sections are also utilized at where necessary.

The below section provides generally on characteristics of teacher training system of Cambodia, then goes on to present the empirical results of the study.

\section{Teacher Training System In CAMBodia}

In Cambodia, the total 12 years of formal education is provided: namely, 6 years for primary education level, 3 years for lower secondary level and another 3 years for upper secondary level. Teacher training is provided at 26 institutions that are divided into four different types: (a) the Pre-School Teacher Training College: PSTTC trains pre-school teachers, (b) 18 Provincial Teacher Training Colleges: PTTCs train primary school teachers, (c) 6 Regional Teacher Training Centers: RTTCs train lower secondary school teachers, and (d) the National Institute of Education: NIE trains upper secondary school teachers. However, due to the shortage of teachers in some areas in the country and to respond to demand of teachers' number in those areas, training formulations have been set out variously among these teacher training centers: TTCs (See Table II).

TABLE II: TRAINING FORMULATION AT TTCS

\begin{tabular}{llll}
\hline \hline \multicolumn{1}{c}{ TTCs } & Period of training & TTCs & \multicolumn{1}{c}{$\begin{array}{c}\text { Period of } \\
\text { training }\end{array}$} \\
\hline PSTTC & $12+2 *$ or $9+2 * *$ & RTTCs & $12+2$ \\
PTTCs & $12+2$ or $9+2$ & NIE & Bachelor+1 \\
Source: $[7]$ & & & \\
Note: $*$ "12+2" or $* *$ “9+2" means 12 or 9 years of formal \\
education plus another 2 years of pedagogical training at any T \\
TCs.
\end{tabular}

The $12+2$ formulation of training is applied for training teachers teaching in lowland provinces, whereas the $9+2$ is applied for training teachers teaching in remote and disadvantaged provinces [7]. This is undeniable that teachers' academic level is still low. According to the Education Staff Indicators 2010-2011 of the MoEYS, the official figure shows that 4.16 per cent of primary teachers do not hold lower secondary school diploma, while 61.58 per cent do not hold upper secondary school diploma. Doubtfully, teachers are seemingly incompetent to provide effective and attractive instructions to children. They might be carrying out the traditional teaching methodologies: for instance, teacher-centered method and 'learning by heart' method or utilize complicated teaching methods. Very significantly for this fact, teacher teaching at basic education level, particularly primary level, is the point in urgent to pay attention for taking proper measure. 


\section{RESUlTS AND DisCUSSION}

There were 200,000 teachers in Cambodia in 1970; but 10 years later after the communist Khmer Rouge regime collapsed in 1979, only 5,000 teachers survived [13], indicated that only 50 of the 725 university instructors, 207 of the 2,300 secondary school teachers, and only 2,717 of the 21,311 primary school teachers [14]. The dearth of school facilities and teacher, particularly trained teachers, remains severe challenges for Cambodia today. In the 1980s, many teachers were deployed to meet demand in school education regardless of their academic level or with-or-without experience in pedagogical training. It is undeniable that teachers who were appointed immediately after 1979 are still working for Cambodian educational institutions presently.

Based on the survey of this paper, it clearly shows that there are 56 persons $(32 \%)$ out of the total 173 respondents have been working for educational sector since Heng Samrin political government period 1979-1990, 51 persons (30\%) have been working since the Paris Peace Accords signed in 1991 , and 43 persons $(25 \%)$ have started working in recent year from 2000 on, though 23 persons (13\%) provided no answer. Within such situation, regarding the experience in participating in in-service teacher training course, the same survey's result demonstrates that besides 11 (6\%) out of 173 respondents provide no answer whether "Yes or No;" 19 respondents $(11 \%)$ answer "No" along with the reason that "because I do not allow to join any in-service training," while $143(83 \%)$ answer "Yes." The specific training courses obtained in this survey can be presented as below:

\section{A. The Training Topics}

Respondents provide 403 training topics of what they participated in the last three years that can be categorized as follows: a) the child rights, b) standard of teaching methodology, c) standard of teacher/trainer, d) producing teaching materials, e) "child friendly school: CFS" program, f) management and life skill, g) information and communication technology: ICT, h) how to use new textbook for grade 1, i) lesson study for grade 10, the first year of upper secondary school in Cambodia' education system, and j) role and duty of school teacher/ principal. These are topics that may apply to the target contents of the EFA goals and MDGs.

\section{B. Place of Conducting the Trainings}

The place of trainings are provided variously and be able to divide into four types as follows: i) 13 topics out of the total 403 topics are held within the school cluster, ii) 27 topics are held within the district, iii) 92 topics are held within the province and iv) 109 topics are held out of the province, whereas the rest of the topics provide no answer whether where they are held.

Obtained such responses, it shows that majority of trainings are provided outside the province that target to educational representatives rather than target to school teachers. This reveals that training opportunities within a school is poorer or very rare.

\section{Duration of the Trainings}

According to the survey, the training periods are also provided variously: a 2-day training course, 3, 5, 7, 10, 12, 14, 15 , and a 20-day course. The longer period is mostly provided in July and August, which are seemingly the months that are suitable with school schedule, as they are the months at the end of an academic school year and, that is, the longest school vacation exists within these months before new academic school year normally starts in October. In contrast, the trainings conducted during the school year are poorer, particularly trainings that include students' participation within a school. Moreover, investigation, observation, or direct evaluation and assessment of concerned officials either never reach the schools properly or regularly.

\section{Supporters of the Trainings}

Many supporters from concerned departments of the government and its development partners provide valuable supports for conducting those courses. The respondents of the survey give comments that they do not remember all the supporters, however based on what respondents provided in the survey sheets, supporters are summarily drown as follows: individual organizations such as European Union: EU, United Nations Educational, Scientific and Cultural Organization: UNESCO, World Food Program: WFP and World bank: WB support few training courses; whereas other individual organizations such as Japan International Cooperation Agency: JICA and Asian Development Bank: ADB support several courses. More than these, MoEYS provides 16 courses, and United Nations Children's Fund: UNICEF supports 91 courses which is the most numerous comparing to the above supporters. Teachers have chances to join some training courses due to those supports.

Obviously, respondents might not take note well for what they used to participate in. On the other hand, having seen all the supports of training programs in Cambodia, because the main supporter of the training is UNICEF, the training contents may be laid on UNICEF's vision.

\section{E. Allowance for Participants of the Trainings}

In Cambodia, teachers usually receive allowance when they participate in any training. However, since the trainings are supported by various organizations, the amount of allowance that teachers received is different. Allowance is provided in US dollar or Khmer Riel; particularly international organizations like UNICEF provides in US Dollar, whereas the government like the MoEYS provides in Khmer Riel. Allowance is provided to training participants according to where it took place and it is really very complicated because it differs according to supporters' budget; for example: 2 US Dollar per day for previously mentioned i), 3-5 US Dollar for ii), 5-15 US Dollar for iii), and 15-30 US Dollar for iv).

In relation with above, conducting and attending in training course are not systematized in Cambodia yet and normally pointed by higher-ranked officials regarding whom to go to attend in a training, and/or through requests of financial supporter and training organizers. In the survey, ways of attending in training course are divided into four kinds: ordered, compulsory, optional and I do not know. Then, the obtained responds can be presented as follows: 200 (49.6\%) out of the total 403 training courses are ordered or pointed by higher-ranked education officials to allow to go 
attending that seemingly happen when there is provider for holding a training course, 62 courses are compulsory which probably occur as technical meetings at the fourth Thursday every month at cluster school, while only 16 courses are optional to attend. With such situation, each training course is desirable to make it more valuable for targeted teachers and concerned educational officials of Cambodia.

\section{F. Perceptions Regarding Usefulness of the Training}

In the survey again, answers to the question 'is each training course useful or not?' are selected from five choice scales: very useful, useful, not useful much, not useful at all, and I do not know. The respondents evaluate as follows: although they do not evaluate anything for the rest of 132 $(32.8 \%)$ courses, they evaluate that $228(56.6 \%)$ out of 403 training courses are very useful, $43(10.6 \%)$ courses are useful.

They give some reasons why they evaluate such usefulness as the following: a) I have chance to acquire new knowledge, new experiences; b) know about 'lesson study,' teachers can work in group and help each other; c) know about educational management, administration, method, pedagogy, how to use new core textbook; d) chance to get to know what 'lesson study' is, how to develop teaching materials, particularly local materials, because it is important to apply in class with students; e) able to manage teaching methodologies more correctly and make students understand easily; f) it is basic for future work; and so on. At the same time, however, they complain that some materials are very difficult to find or produce, and that produced materials are very few. They additionally criticize that duration of training is too short, and the consistency between what they have gained at training courses and the implementation at actual situation of workplace is far different. For whatever the content of training course, it is desirable if it is useful and applicable in Cambodia's educational situation and context. As described above, it is possible to argue that respondents realize the importance of the training provided so far; but truly, they are demanding flexible and feasible ones.

\section{G. Awareness Regarding the Significance of INSET}

Respondents indicate explicitly regarding the importance of in-service teacher training course as presented in the previous section. To reveal the awareness of the significance of in-service teacher training: INSET, a question: 'is in-service teacher training important for improving teacher's quality and teacher's status?' is also designed in the survey with six choice scales of answers are provided: very important, quite important, moderately important, not so important, not important at all, and I do not know. As result, although the $12(6.9 \%)$ respondents out of the total 173 respondents do not choose any optional answer, $150(86.7 \%)$ answer 'very useful,' whereas $9(5.2 \%)$ answer 'quite useful,' and the other 2 (1.1\%) answer 'moderately useful.' This is a positive awareness and recognition of respondents toward the significance of the in-service teacher training program for their professional development.

\section{CONCLUSION AND RECOMMENDATIONS}

Overall, this study reveals that Cambodia faces severe situation, essentially the acute shortage of qualified teachers. The data used in this paper tell teacher's low academic record, some teachers have never participated in pedagogical training, and it is possible to say that in-service training for teacher is inappropriate for Cambodia's educational context. The most urgent action is required to take accordingly such as measures that response to the right time and right place of needs, especially for those in rural areas if Cambodia intends to achieve delivering quality of basic education for all by 2015 or in the future later than that.

Educational opportunities for all children in the whole Cambodia are still limited; in particular children in rural areas, in remote areas, in disadvantaged areas, disabled children and non-Khmer mother tongue children. It is the rationale that basic education needs to be set as priority stage for children in these areas. Furthermore, the purpose of education, the view of school, and the image of teacher needs to be clearly identified. In Cambodia, presently, many of the structures and conditions required to provide to education are still incomplete and not yet suitably put in place. More particularly, professional competences of many teachers leave a great deal to be desired [15]. While the psychological, material and geographical situations of teachers varies from country to country or from area to area; their essential post is desired to be respected and recognized by children and society. At the same time, teacher is pivotal to be given necessary authority and suitable resources as well as proper opportunities. These are imperatively required for them to gain up-to-date knowledge and skills as well as teaching methodologies so as to become more proficient in order to share benefits not only for the quality improvement of education but also for various corners of economic, social and cultural segments [16]. With this regards, it requires to observe and examine the conditions of teachers concerning key components such as current problems and issues related to teachers' competences, teacher needs and demands, and opportunities for the professional development in in-service programs of teachers in urban, rural, and remote areas [3].

In short, ensuring qualified teachers in Cambodia is no easy task since many of teachers hold low academic records, while some teachers have not experienced the pedagogical training. Where there have no or less academic qualification and inadequate training, the critical importance of in-service programs for teachers become evident. In Cambodia, regular in-service training for teachers has not been systematized, provided trainings so far are under supports from the government and development partners just once in a while. Therefore; despites the supports from the government, supports and participation from community in improving the quality of teacher's teaching and children's learning are indispensable. In so doing, teachers are able to conduct ongoing professional development in a series of suitable and feasible in-service training. Furthermore; since teachers, respondents in this study, also presents their demand in the present survey about applicable in-service training, so analyses of a survey on what kinds of training they need, based on another section of this questionnaire survey, is to be revealed and presented in another paper.

All above, teacher is appreciated to conduct ongoing professional development, for example: through individual 
research, school-based in-service training and so on to get to understand the new national curriculum approach and to develop new skills such as the ability to communicate, to learn from each other, to open school to society, to design learning material, to engage in self-managing school and to change school to become more enjoyable learning organization [17]. There is no objection that enabling the professional development of teachers is indispensable for the quality education at all levels and it cannot be made without incessant training and efforts made by teachers themselves [3]. Teachers require making time positively to join all training opportunities provided. So, teacher may have better performance because they have obvious understanding of their school's condition and therefore they may provide their full potential for the quality improvement of their school, children's learning, and for the quality improvement of education as a whole as well as for human and social development of a nation.

\section{ACKNOWLEDGMENT}

The author would like to express heartfelt thanks to supervisor, Prof. Shinji Kubota, for his continuous support, guidance, encouragement and illumination for the research. Likewise, sincere gratitude also goes to her father, Chham Phin, for his invaluable sources providing from distance from Cambodia, her home country. Last but not least, profound thanks also go to her husband, relatives and other people whose names are not mentioned for their spiritual support.

\section{REFERENCES}

[1] United Nations Educational, Scientific and Cultural Organization: UNESCO, Teaching and learning for development, 2013 Education for All Global Monitoring Report-Review, 2013.

[2] UNESCO, "Youth and skills: Putting education to work," 2012 Education for All Global Monitoring Report, 2012.

[3] UNESCO, "Ensuring opportunities for the professional development of teachers," Seminar Report, Hiroshima: Japan, 1998.

[4] Education International: EI. (21 Apr 2013). Every child needs a teacher [Online]. Available: http://www.ei-ie.org/en/news/news_details/2545.

[5] B. Kiernan, "The nature of the Genocide in Cambodia (Kampuchea)," Social Education, vol. 55, no. 2, pp. 114-115, 1991.

[6] T. Clayton, "Building the new Cambodia: Educational destruction and construction under the Khmer Rouge, 1975-1979," History of Education Society Quarterly, vol. 38, no. 1, 1998.
[7] Ministry of Education, Youth and Sport: MoEYS, Teacher Development Master Plan 2010-2014, Phnom Penh: MoEYS, Aug 2010.

[8] MoEYS, Education Statistics \& Indicators 2011-2012, EMIS Office, Department of Planning, Phnom Penh: Cambodia, Feb 2012.

[9] MoEYS, Education Staff Statistics by Current Status, Cadre, Qualification and Age Group National 2010-2011, HRMIS Office, Department of Personnel, Phnom Penh: MoEYS, Jul 2011.

[10] J. Courtney, "What are effective components of in-service teacher trainings? A study examining teacher trainers' perceptions of the components of a training programme in mathematics education in Cambodia," Journal of In-service Education, vol. 33, no. 3, pp. 321-339, 2007.

[11] V. R. Khlok, "A study of teacher education in Cambodia-The development of training system and standards," Bulletin of the Graduate School of Education and Human Development (Educational Studies), Nagoya University, vol. 48, no. 1, pp. 57-70, 2001.

[12] V. R. Khlok, "The re-establishment of cambodian education system after the pol pot regime: The study of Vietnamization and Re-Khmerization," The Japanese Journal of Educational Research, vol. 70, no. 3, pp. 383-392, 2003.

[13] Cambodia Independent Teachers Association: CITA's pamphlet, Protecting and Promoting the Rights of Teachers in Cambodia, Phnom Penh: Cambodia

[14] Library of Congress: LoC. (na). A Country Study: Cambodia. Library of Congress Call Number DS554.3.C34 1990. [Online]. Available: http://lcweb2.loc.gov/frd/cs/khtoc.html.

[15] Japan International Cooperation Agency: JICA, The History of Japan's Educational Development-What implications can be drawn for developing countries today, Tokyo: Japan, 2004.

[16] J. Delors et al., Learning: The Treasure Within, UNESCO Publishing: Paris, 1996.

[17] S. A. M. Reza and M. Matoba, "Challenges in Japanese Teachers' Professional Development: A Focus on an Alternative Perspective," Comparative Education Society \& Bureau for Educational Services, Bulgarian, vol. 4, pp. 107-116, 2006.

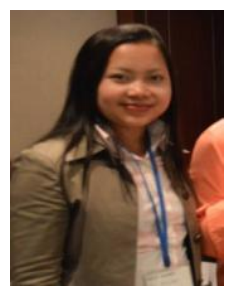

Chankea Phin is a doctoral candidate in Educational Sciences, major in Educational Governance: Policy and Politics at University of Tsukuba, Ibaraki Prefecture, Japan. She began her career as a primary school teacher in 2000 in Svay Rieng province of Cambodia, then became a lower secondary school teacher of English at Wat Koh high school in Phnom Penh in 2006, and later she was selected in 2007 to be dispatched to join "the $28^{\text {th }}$ batch in-service training program for overseas teachers" at University of Tsukuba. She has pursued her study at this university and received her master degree in Education Sciences in 2011. Her research interests include proper-and-feasible policies surrounding teacher education, specifically primary school teacher. 